\title{
Vivências de travestis \\ no acesso ao SUS
}

| ${ }^{1}$ Breno de Oliveira Ferreira, ${ }^{2}$ Elaine Ferreira do Nascimento,

${ }^{3}$ José Ivo dos Santos Pedrosa, ${ }^{4}$ Liana Maria Ibiapina do Monte I

Resumo: Reconhecendo que as travestis enfrentam discriminação por conta da sua identidade de gênero, gerando com isso processos de adoecimento e sofrimento próprios de estigmas associados, o estudo teve por objetivo analisar e compreender as vivências de travestis acerca da atenção à saúde no SUS em Teresina-PI. Para o desenho metodológico, realizou-se pesquisa qualitativa, em que participaram seis travestis que residem em Teresina, e que de forma direta ou indireta acessam os serviços de saúde. As participantes foram selecionadas pela técnica metodológica Snowball, e a coleta dos dados se deu através de grupo focal. O Método de Interpretação de Sentidos foi utilizado para análise, tratamento e interpretação dos fenômenos sociais. Como resultado e discussão, foram identificadas as categorias: fragilidades no atendimento e especializaçấo do cuidado. $\mathrm{O}$ trabalho considerou a necessidade de mais integração entre os diversos segmentos sociais e os serviços de saúde, a qualificação dos profissionais para garantir o acolhimento às travestis e a urgência de se refletir sobre o caráter discriminatório dos serviços especializados implantados pelo SUS, ainda que sejam uma possibilidade de porta de entrada delas ao órgão de saúde.

> Palavras-chave: identidade de gênero; Sistema Único de Saúde; equidade.

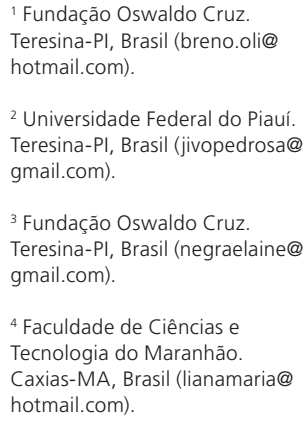

${ }^{1}$ Fundação Oswaldo Cruz. Teresina-PI, Brasil (breno.oli@ hotmail.com).

2 Universidade Federal do Piauí. Teresina-PI, Brasil (jivopedrosa@ gmail.com).

${ }^{3}$ Fundação Oswaldo Cruz. Teresina-PI, Brasil (negraelaine@ gmail.com).

${ }^{4}$ Faculdade de Ciências e Tecnologia do Maranhão. Caxias-MA, Brasil (lianamaria@ hotmail.com). 


\section{Introdução}

O diferente sempre despertou perplexidade e resistência ao longo da humanidade, e as travestis, segundo Butler (2003), reinventam a realidade do gênero pela via das múltiplas performances sociais, ou seja, a perspectiva de gênero pode, a partir da abordagem social, assumir diversos arranjos, abrindo diferentes possibilidades de fluidez. À medida que o corpo se constitui como uma realidade inicial e imediata, o gênero se faz presente.

$\mathrm{O}$ mesmo pode ser problematizado para as discussóes que se voltam para o campo das identidades, sobretudo das sexuais (RAMALHO, 2005). A identidade, por ser uma representação social, também é móvel, oriunda de processos que envolvem a mobilidade das relaçóes, a qual se inscreverá em scripts sexuais e culturais da formaçáo dos sujeitos (BOZON, 2004).

No que se refere à identidade sexual, os atributos e os atos de cada sexo são performativos, uma vez que no mundo globalizado, as expressóes de gênero já não são presumíveis, mas sim potencializadoras de espaços de liberdade, de transitoriedade e de alternativas (BUTLER, 2003), além de a sexualidade ser dotada de plasticidade (GIDDENS, 1993) e fluidez.

Gênero, portanto, pode ser definido como um produto social que é assimilado, representado, institucionalizado e repassado de uma geração para outra, traçando parâmetros do que é ser homem e ser mulher. Nesse sentido, o gênero estrutura relaçôes de poder desiguais, fazendo com que a mulher ou o que se configura feminino permaneça, quase sempre, em uma posição subalterna na organização da vida social.

Essa assimetria das relaçóes ainda incita resistências, especialmente àquelas relativas aos processos discriminatórios. E quando se estende para o campo da saúde, sobretudo no que se refere ao acesso às açóes e serviços básicos e especializados, parecem existir diversas vulnerabilidades (ROMANO, 2008; LIONÇO, 2008).

A vulnerabilidade é um movimento que pode aumentar a chance de exposição do usuário à doença através de cenários individuais, coletivos e contextuais que reverberam em maior ou menor suscetibilidade ao adoecimento. Portanto, Ayres et al. (2003) destacam três eixos que se interligam à vulnerabilidade. $\mathrm{O}$ componente individual, por meio do nível de conhecimento e informaçóes dos sujeitos sobre o processo saúde-doença, bem como seus fatores de riscos e de 
proteção. O componente social, como o poder de transformação e mudanças

práticas no cotidiano dos usuários. E o componente coletivo, que se refere ao compromisso e qualidade dos serviços ofertados.

Ancorando-se no conceito de vulnerabilidade, Lionço (2008) sinalizou a necessidade de uma política de saúde específica para a população LGBT (lésbicas, gays, bissexuais, travestis e transexuais), fundamentada na promoção da equidade, a partir da reflexão e reconhecimento das condiçôes de vulnerabilidades em que se encontram esses sujeitos.

Em 2011, foi publicada a Política Nacional de Saúde Integral da População LGBT, como resposta às demandas e especificidades emudecidas da populaçáo LGBT, com o intuito de promover cidadania e efetivar uma política pública de garantia de direitos (BRASIL, 2013).

Contudo, para efetivação da política de saúde LGBT, o acesso se dá como um componente essencial para a legitimidade do atendimento a essa população. Andersen (1995) conceitua acesso como um elemento basilar na estrutura de qualquer serviço de saúde, refere-se à entrada dos usuários nos serviços, desde a utilização das ofertas, até o final do tratamento ou participação das açôes oferecidas. Isto é, os cuidados proporcionados precisam gerar resultados positivos em saúde.

Já Donabedian (2003) preferiu não restringir o acesso à entrada e utilizou a terminologia acessibilidade dentro de um contexto mais ampliado, em que a lógica organizacional está para além da disposição dos recursos em uma dada circunstância. Entretanto, abrange a oferta de possibilidades da população em utilizar os serviços de saúde. Assim, há uma adequação às diferentes especificidades dos usuários para incluí-los no sistema.

Unglert (1995) traz o conceito de acesso em três dimensôes: o acesso geográfico, caracterizado pelo deslocamento, tempo, tipo de transporte e a distância até o serviço de saúde; o acesso econômico, que trata dos fatores que obstaculizam ou facilitam a utilização dos serviços, como os custos e gastos para o deslocamento; e o acesso funcional, que engloba a entrada propriamente dita nos serviços de saúde, que inclui os tipos de açóes ofertadas, os horários previstos para funcionamento e a qualidade do acolhimento.

$\mathrm{O}$ acesso funcional é a dimensão que faz menção direta às (im)possibilidades de inserção de travestis no SUS, que por conta de não terem uma adequação de 
gênero com o sexo biologicamente posto, representando em si a diferença, sofrem discriminação e podem ter seu direito de acesso à saúde violado (MELLO; AVELAR; MAROJA, 2012).

Diante das barreiras discriminatórias ou pela falta de acolhimento nos serviços de saúde, as travestis podem buscar um atendimento precário nos serviços clandestinos, o que pode trazer riscos para a saúde em geral e, consequentemente, aumentar suas vulnerabilidades, fatos estes que apontam para a necessidade de aumentar o uso de tecnologias leves no cuidado em saúde (MERHY, 1997).

Nessa concepção, mesmo sendo escassos os dados que denotam o impacto das diferentes formas de discriminação - como a travestifobia nas condiçôes de saúde -, os saberes da Saúde Coletiva são suficientes para sustentar a necessidade de qualificar a articulaçáo de políticas de saúde mais específicas que promovam práticas sociais e institucionais que não permitam a estigmatização e marginalização das pessoas e de suas identidades de gênero.

Com isso, o presente estudo reúne vivências e reflexôes de travestis acerca da atenção à saúde no SUS. Com o intuito de ampliar os conhecimentos científicos aliados às representaçôes desses sujeitos, foram analisadas diferentes situaçôes de vulnerabilidades de travestis ao acessar os serviços de saúde em Teresina, Piauí.

Destaca-se que a análise deste estudo esteve relacionada ao desenvolvimento da pesquisa intitulada "Análise do acesso e da qualidade da atenção integral à saúde da população LGBT no SUS", coordenada pelo Núcleo de Estudos em Saúde Pública da Universidade de Brasília (NESP/UnB), em parceria com várias Universidades Federais (Piauí, Paraíba, Uberlândia e São Paulo), Universidades Estaduais (Rio de Janeiro e Maringá) e a Fiocruz de Pernambuco. No Piauí, o grupo condutor foi constituído por membros do Núcleo de Estudos em Saúde Pública da Universidade Federal do Piauí (NESP/UFPI). A pesquisa foi financiada pelo Departamento de Apoio à Gestáo Participativa (DAGEP) da Secretaria de Gestão Estratégica e Participativa (SGEP) do Ministério da Saúde (MS).

\section{Desenho metodológico}

Trata-se de um estudo de abordagem qualitativa que responde a questôes muito particulares da proposta em questão e discute especialmente significados, sentimentos, opinióes, atitudes, entre outras características inerentes à subjetividade humana, presentes em travestis usuárias do SUS na cidade de 
Teresina, capital do estado do Piauí. Esse conjunto de fenômenos é entendido como parte da realidade psicossocial, pois o sujeito se distingue não só por agir, mas por pensar sobre o que faz e por interpretar suas açóes dentro e a partir da realidade vivida e partilhada com seus pares, o que justifica a proposta qualitativa do trabalho (MINAYO, 2002).

Em termos relativos, os estados da Paraíba e do Piauí e suas respectivas capitais são os locais que oferecem maior risco de morte violenta para LGBTs: enquanto no Brasil como um todo, os LGBTs assassinados representam 1,6 de cada milhão de habitantes, na Paraíba esse risco sobe para 4,5, e 4,1 para o Piauí, segundo dados apontados pelo Grupo Gay da Bahia (GGB) e divulgados em 2015 no Relatório Anual de Assassinatos de LGBT no Brasil, em 2014. Destaca-se que as travestis e transexuais foram apontadas como as mais violentadas do grupo (GGB, 2015).

A participação das escolhidas ocorreu considerando a disponibilidade e o interesse em fazer parte da pesquisa, consentida por meio do Termo de Consentimento Livre e Esclarecido. Sobre esse fato, destaca-se que foi realizado o convite para as travestis através de contatos com membros de ONGs, grupos de ativistas, militantes ou representantes na luta pelos direitos humanos. Com esse intuito, utilizou-se a técnica metodológica intitulada Snowball, em que se parte de sujeitos iniciais, que, por sua vez, indicam novos participantes, que continuam a indicar outros sujeitos, prolongando-se, assim, até que os objetivos sejam alcançados. Empregou-se, portanto, cadeias de referências dentro da rede de contatos (WHA, 1994).

No estudo, utilizou-se também a técnica de grupos focais, que, segundo Trad (2009), possibilita uma ampla problematização acerca de um tema específico. Originária da pesquisa social, desenvolveu-se por meio da perspectiva dialética, na qual o grupo possui objetivos comuns e seus participantes são intencionalmente conduzidos a um espaço de discussão e troca de experiências.

Debus (2004) esclarece que o grupo focal oferece a possibilidade de discussôes sobre questôes particulares, sem a intenção de saturar debates, mas desnudar as subjetividades da temática explorada. Assim sendo, foi realizado um encontro seguindo roteiro previamente elaborado, planejado, moderado por um pesquisador e observado por outros pesquisadores e/ou auxiliares de pesquisa. O grupo focal contou com a participação de seis travestis e ocorreu no mês de junho de 2015. 
Todos os áudios foram registrados por meio de um mp4 portátil, posteriormente transcritos na íntegra e em seguida, analisados. Para tanto, as informaçóes coletadas no grupo focal foram trabalhadas a partir do Método de Interpretação de Sentidos (GOMES et al., 2005), o qual se baseia em princípios hermenêuticodialéticos que buscam interpretar o contexto, as razôes e as lógicas das falas.

Quanto às questóes éticas da pesquisa, foram submetidas e aprovadas pelo Comitê de Ética em Pesquisa da Universidade de Brasília (UNB), conveniandose ao Núcleo de Saúde Pública (NESP) da Universidade Federal do Piauí (UFPI), com parecer de CAAE 25856613.9.0000.0030.

\section{Tecendo discussóes}

O grupo focal com as travestis ocorreu em um único encontro, com seis participantes (Margarida, Rosa, Copo de Leite, Lírio, Orquídea e Girassol), na residência de uma delas e no turno da noite, por ser um horário de maior disponibilidade da maioria. O grupo teve duração de 2 horas e 20 minutos e obteve grande participação e interação entre os sujeitos.

As participantes já tinham vínculo anterior à pesquisa e conhecimentos prévios das histórias de vidas, percalços e caminhos enfrentados em seus processos de mudança corporal. Todas são residentes em Teresina e acessam o SUS, seja em maior ou menor proporção.

No decorrer do grupo focal, na transcrição do material e na leitura qualificada, duas categorias foram apontadas como de maior frequência, e estas foram descritas e analisadas conforme as categorias temáticas.

\section{Categoria 1: Fragilidades no atendimento às travestis}

Ao adoecer, de maneira geral, o sujeito se fragiliza em seu campo biológico, psicológico e social, isto é, o sujeito adoece como um todo, o que o direciona para cuidados específicos da atenção à saúde. Contudo, tal cuidado precisa ser necessariamente ético, e a humanização, relacionada à organização do serviço de saúde, fortalece-se enquanto elemento fundamental para o atendimento ético, respeitoso e humanizado, na medida em que se preconiza no artigo 196 da Constituição Brasileira que a saúde é direito de todos e dever do Estado (BRASIL, 1988). 
Destarte, quando as travestis não se sentem à vontade nos serviços de saúde, é comum se fragilizarem. Cerqueira-Santos et al. (2009) esclarecem que tais dificuldades podem ter sido oriundas da equipe de profissionais de saúde, que, por sua vez, podem ter manifestado situaçóes de preconceito. Essas situaçóes, consequentemente, acabam desencorajando e fazendo com que as travestis procurem outros itinerários terapêuticos. As falas ilustram ainda mais esses entraves:

\footnotetext{
Eu já me considerava bem velha e coloquei silicone. Já vai fazer 10 anos, já me internei 11 vezes, e já comi o pão que o diabo amassou no SUS (GIRASSOL).

Pra mim, não existe sistema de saúde pra nós travestis, a gente é apenas motivo de chacota (ROSA).
}

Os percalços de Girassol e Rosa apontam com clareza para uma verdadeira batalha diante das desigualdades do SUS, destacando a necessidade de mudanças significativas nas práticas em saúde, com alusão para a inseparabilidade básica entre essas práticas conduzidas e os seus sujeitos - as travestis. Acontece que muitas delas, a fim de se tornarem inteligíveis, isto é, socializarem-se mediante a desconformidade do seu corpo, realizam várias mudanças corporais na busca de uma aparência mais próxima do feminino, que as identifique como tal.

Contudo, Santos (2013) destaca que esse corpo modificado é frequentemente alvo de várias interdiçóes, as quais contribuem para agravar ainda mais a situação de saúde, e que, além disso, trata-se de um "corpo fabricado", que ao circular pelos diferentes espaços, atrai sobre si alguma forma de violência.

Esse processo de forja dos seus corpos ocorre na clandestinidade e sem nenhum tipo de segurança, uma vez que as travestis são ou estão invisíveis para o Estado e, portanto, para o SUS. As travestis acabam lidando com experiências de quase morte constantemente pelo fato de não existirem como sujeitos nem serem consideradas clientelas legítimas dos serviços de saúde. Assim, a busca pela redefinição do corpo se dá numa perspectiva solitária, exposta e desprotegida, além de estar envolta em um silêncio público.

Ressalta-se que as próprias intervençóes que conduzem para a mudança corporal são permeadas de riscos e sequelas provenientes da forma artesanal e carente de biossegurança na qual esse processo ocorre muitas vezes realizado por travestis conhecidas como bombadeiras, que clandestinamente são contratadas para fazer mudanças nos corpos de outras travestis a fim de deixá-las mais 
1030 femininas. Realizam, por exemplo, a aplicação de silicone industrial em diversas partes do corpo, como quadril, nádegas e rosto.

No entanto, essas práticas não são legalizadas pelo Conselho Federal de Medicina (CFM) e podem trazer prejuízos à saúde de quem a elas se submetem. Com isso, é comum elas acessarem os serviços de saúde para tratar de algum problema decorrente dessas ações clandestinas de modificação do corpo, ressaltando que essa entrada ocorre numa abordagem de ausência total de acolhimento.

Portanto, a garantia do acesso para assistência em saúde, quando analisada na perspectiva da disponibilidade dos serviços, poderia apresentar o profissional de saúde enquanto promotor das relaçóes, como articulador face aos conhecimentos, as tecnologias disponíveis e ao aparato físico, já que são esses trabalhadores que se materializam em atos de saúde capazes de não patologizar, não desumanizar nem estigmatizar as travestis (ASSIS et al., 2003; SANTOS, 2013). No caso das travestis, esse acolhimento chega atravessado pela ausência dos cuidados primários que são dispensados a elas.

Destacando a política LGBT nesse campo, os profissionais são essenciais na estruturaçáo do acesso das travestis aos diferentes serviços, sobretudo porque podem (ou não) escutar e perceber, de forma qualificada, as demandas latentes e então se mobilizarem de maneira a propor uma reorganização que reflita tal necessidade e suas especificidades. Em decorrência disso, os treinamentos e capacitaçóes devem ser algo frequente nos serviços, como um espaço para discutir e reforçar temas relacionados à saúde LGBT.

Muller e Knauth (2008) afirmam que esse atendimento, no caso das travestis, "é babado", colocando a linguagem utilizada pelo profissional de saúde como um entrave que pode gerar resistências capazes de distanciar as travestis dos serviços e fomentar a não adesão ao tratamento. Dessa forma, percebe-se que o universo das travestis precisa ser mais compreendido, pois a falta dessa qualificação no atendimento pode gerar questóes mais severas e resistências em longo prazo. A transcriçãoo da fala de Copo de Leite mostra sua relação de insegurança.

Quando eu sei que preciso ir ao hospital eu já me sinto insegurança, lá vai sofrer a travesti outra vez no hospital (COPO DE LEITE).

O depoimento de Copo de Leite reafirma o universo de insegurança e até mesmo medo de ser travesti e precisar de um serviço público, que a princípio 
deveria cuidar de você, mas não o faz, fato que remonta à necessidade de estratégias mais protetivas, que promovam a minimização de seu sofrimento diante de tantas alteraçóes corporais. A forma com que estas participantes foram atendidas nos serviços de saúde mostra como se configura a violência institucional, que, segundo Lionço (2008), acontece por conta de padrôes heteronormativos que predominam nos discursos conservadores e morais, nos quais o heterossexual é tido como a norma.

Bourdieu (2004) segue a mesma linha ao definir aspectos da violência como uma unidade que se quer parecer natural, mas não o é. $O$ princípio da violência se ancora numa abordagem de cultura simbólica, sendo esta uma questão arbitrária, uma vez que não se assenta numa realidade dada como natural, ou seja, o sistema simbólico de uma determinada cultura é uma concessão social, e sua manutenção é fundamental para a perpetuação de uma determinada sociedade, através de interiorização da cultura por todos seus membros. Assim, ser travesti em nossa sociedade é a obtenção de um salvo conduto para os serviços de saúde fazerem uso de violência, porque "naturalmente" é negado às travestis o passaporte de cidadania.

Com o objetivo de coibir a reprodução dessas práticas arraigadas na realidade do Piauí, a Lei Ordinária no 5.431, de 29 de dezembro de 2004, dirige-se às sanções administrativas a ser aplicadas à discriminação em razão da identidade de gênero. Em seu artigo $5^{\circ}$ afirma que a travesti ou transexual que for vítima de atos discriminatórios ou vexatórios poderá apresentar sua denúncia pessoalmente ou por carta, telegrama, telex ou via internet ao órgão estadual competente e/ou as organizaçôes não governamentais de defesa da cidadania e direitos humanos, garantindo ainda no $₫ 1^{\circ}$ o sigilo do denunciante. $\mathrm{O}$ artigo $6^{\circ}$ elenca as possibilidades de sançóes, entre elas: a advertência, multa, interdição do estabelecimento, suspensão da licença para funcionamento (Lei Ordinária ${ }^{\circ}$ 5.431, de 29 de dezembro de 2004).

Destaca-se que em maio de 2015 foi lançado o curso a distância intitulado "Política de Saúde LGBT", que se tornou um marco entre os cursos da Universidade Aberta do SUS (UNA-SUS), com base na promoção do respeito à diversidade e com o objetivo de capacitar os profissionais de saúde para um atendimento qualificado e humanizado à população LGBT, e como uma forma também de facilitar a reflexão e levar ao empoderamento dessas temáticas para o exercício de respeito e cidadania da população LGBT. 


\section{Categoria 2: Especialização do cuidado às travestis}

O filósofo Leonardo Boff conceitua cuidado como uma atividade de zelo, desvelo e responsabilidade para com o outro (BOFF, 2002). Quando trazida para o campo da saúde, o cuidado se relaciona com o direito de ser, isto é, respeitar o direito de ser é cuidar dos sujeitos em suas particularidades. Portanto, o cuidado em saúde se traduz em atitudes e açôes integrais com vistas a gerar consequências positivas entre os usuários, trabalhadores e gestores do SUS (AYRES, 2001).

E será que as diferentes vulnerabilidades das travestis são acolhidas no SUS? Logo, a provocação feita pelo princípio da equidade desafia os serviços de saúde a perceberem as travestis em suas singularidades e, ao mesmo tempo, incita uma (in)formação no campo das políticas afirmativas de acesso para que valorizem sua inclusão e proteção no SUS. Com isso, os autores acordam consensualmente que é necessário o enfrentamento da travestifobia nos serviços de saúde, sendo esta uma estratégia basilar na garantia do cuidado dessa população (MELLO; AVELAR; MAROJA, 2012; LIONÇO, 2008; PELÚCIO, 2011).

A produção social das travestis é percebida também pelo Ministério da Saúde, que reconhece a identidade de gênero como determinante e condicionante da situação de saúde, não só por implicar práticas sexuais e sociais específicas, mas também por favorecer a exposição desses sujeitos a agravos decorrentes do estigma e da própria exclusão social (BRASIL, 2013). Nesse sentido, estratégias têm sido adotadas para diminuir os efeitos dessa exclusão, melhorar a qualidade da assistência e fortalecer o vínculo de cuidado, especialmente com o grupo das travestis.

Entre elas, a Secretaria Estadual de Saúde de São Paulo despontou, em 2009, com a criação do primeiro ambulatório especializado exclusivo para atender às demandas específicas de travestis e transexuais (femininas e masculinos), e que, segundo Gianna (2011), teve o intuito de contribuir para a integralidade no cuidado, a humanização da atenção e a promoção de um atendimento sem discriminação.

O serviço é formado por equipe multiprofissional (médicos, assistentes sociais, psicólogos, enfermeiros e fonoaudiólogos) e oferece os seguintes serviços: acolhimento; aconselhamento (adoção de medidas de autocuidado, redução de danos em relação à hormonioterapia, uso de silicone); avaliação proctológica, urológica, ginecológica, endocrinológica, de clínica geral e em saúde mental; psicoterapia individual e em grupo; e atendimento social (GIANNA, 2011). 
Algumas falas denotam a importância da criação desses espaços (ainda que existam críticas em relação a sua perspectiva discriminatória) e descrevem cenas vexatórias vivenciadas por travestis no SUS ao procurarem um médico proctologista, no caso de Girassol, e um urologista, no exemplo de Lírio.

Eu até falei com uma amiga pra ela marcar um proctologista pra mim, mas como é
que eu vou chegar, uma mulher, para ir ao médico que é de homem? Aí ela ficou sem
me responder, eu pra quebrar o gelo disse a ela que eu não queria exame de sangue,
queria a dedada, só pra descontrair (GIRASSOL).
Aí elas ficaram sem entender porque eu ia era para o urologista, foi um sacrifício pra
elas entenderem que não era pra lá que eu ia, mas eu não disse que era, fiquei caladi-
nha, peguei minha bolsa e entrei no urologista. Entendeu? (LÍRIO).

Nesse contexto, percebe-se, a partir dos relatos, que a criaçáo de um ambulatório especializado para atender às demandas específicas de travestis é uma proposta que pode minimizar as desigualdades, especialmente para esse segmento. Existem hoje no Brasil seis ambulatórios especializados funcionado nos moldes do criado em São Paulo e todos ligados aos serviços de IST e AIDS, sendo apenas um localizado no Nordeste, na Paraíba, que já é referência nacional.

Seguindo esse caminho, o Piauí já possui articulação do movimento social com a Secretaria Estadual de Saúde para que seja implantado esse tipo de atenção própria para as travestis, no entanto, ainda encontra-se em fase de estudo e análise situacional.

Diante da ampliação e, ao mesmo tempo, delimitação de espaços desses “corpos fabricados", Pelúcio (2011) questiona que a travestilidade, em sua maioria, associada à centralidade dos valores estético-morais, acaba por esvaziar a força das estratégias que de antemão eram de cuidado, sobretudo quando o discurso não se faz acompanhar de uma política que possa atender às demandas efetivas das travestis no que se refere à segurança, cidadania e principalmente à saúde.

E principalmente no campo da saúde, há um consenso que os serviços têm buscado melhorias e qualificaçôes para o acolhimento das travestis (GIANNA, 2011), contudo, esses novos espaços de diálogo, como os serviços especializados, têm apontado para um efeito perverso, isto é, o confinamento de travestis a unidades especializadas em IST e AIDS. Dessa forma, há um condicionamento dos problemas de saúde às questóes de IST e AIDS (PELÚCIO, 2011).

É importante destacar que "esses" corpos fabricados podem estar impedidos de circular mais livremente por espaços legitimamente públicos, sendo que apenas 
alguns corpos fabricados serão cerceados, como afirma Foucault (1999), já outros serão plenamente enaltecidos. Outros corpos que em tese são produzidos em espaços legítimos (como nas academias, por exemplo) tendem a se tornarem um modelo estético a ser perseguido. Nesse caso, eles poderão circular à luz do dia, não serão impedidos de exercitar o direito civil de ir e vir, além de serem muito bem-vindos em qualquer espaço e serviço.

Os discursos serão engendrados e voltados para fazer deles a norma. Desta feita, mais uma vez as travestis ficam marginalizadas, podendo transitar apenas quando todos os "gatos são pardos", ou seja, quando "ninguém" as vê. Os serviços de saúde, portanto, partilham dessa armadilha sociocultural da contemporaneidade que valora a norma em detrimento da diversidade no campo dos direitos humanos.

As indagações de Pelúcio (2011) articuladas com Foucault (1999) tencionam reflexões na condução dessa organização nos serviços e também no investimento moral atrelado a estes movimentos de inclusão/exclusão. Não se defende apenas a construçáo de uma rede com dispositivos prontos para atender às demandas das travestis, mas também qualificação e possibilidade de reorganização da rede em geral, e que esta garanta o acesso universal, náo uma reproduçáo machista e patriarcal de segregação de espaços.

\section{Considerações finais}

Muitos desafios são postos para garantir o acesso das travestis nos serviços de saúde. Nesse sentido, a discriminaçáo foi citada por todas as participantes da pesquisa, mostrando que o SUS acaba refletindo os valores de uma sociedade que coloca o sujeito heterossexual como padrão. Isso traz sérios prejuízos ao SUS, ferindo seu princípio mais basilar, que é a universalidade.

Destaca-se que a discriminação pode ainda levar as travestis a procurarem pelo atendimento precário de serviços clandestinos de modificação corporal, podendo acarretar riscos para sua própria saúde e fazendo ainda com que aumente as situações vulnerabilizadoras. Fato este que aponta para a necessidade de um acolhimento "humanizado" nos serviços públicos de saúde.

Por um lado, a criação de serviços específicos como proposto pelas participantes é uma estratégia importante para legitimar a garantia do acesso ao SUS e permitir uma especialização mais qualificada do cuidado, já que muitas 
delas têm "entrado pelas portas dos fundos nos serviços de saúde"; mas por outro, a exclusividade desses serviços pode acarretar armadilhas de estigmatização, uma vez que a fabricação de seus corpos pode (ou não) engendrar invisibilidades na sociedade, em meio a mecanismos de se tornarem inteligíveis. ${ }^{1}$

\section{Referências}

ANDERSEN, R.M. Revisiting the behavioral model and access to medical care: does it matter? J Health Soc Behav. USA, v. 1, n.36, p. 1-10, 1995.

ASSIS, M.M.A. et al. Acesso aos serviços de saúde: uma possibilidade a ser construída na prática. Ciência e Saúde Coletiva. Rio de Janeiro, v. 8, n. 3, p. 815-823, 2003. Disponível em: $<$ http://www.scielo.br/scielo.php?script=sci_arttext\&pid=S1413-81232003000300016>. Acesso em: 10 ago. 2016.

AYRES, J.R.C.M. Sujeito, intersubjetividade e práticas de saúde. Ciência \& Saúde Coletiva. Rio de Janeiro, v. 6, n. 1, p. 63-72, 2001.

AYRES, J.R.C.M. et al. O conceito de vulnerabilidade e as práticas de saúde: novas perspectivas e desafios. In: CZERESNIA, D.; FREITAS, C.M. (Orgs.). Promoção da saúde: conceitos, reflexôes, tendências. Rio de Janeiro: Fiocruz, 2003, p. 117-140.

BOFF, L. Saber cuidar: ética do humano, compaixão pela terra. Petrópolis: Vozes, 2002.

BOURDIEU, P. O poder simbólico. Rio de Janeiro: Bertrand Brasil, 2004.

BOZON, M. Sociologia da sexualidade. Rio de Janeiro: FGV, 2004.

BRASIL. Constituição da República Federativa do Brasil. Brasília: Senado Federal, 1988. . Ministério da Saúde. Política Nacional de Saúde Integral de Lésbicas, Gays, Bissexuais, Travestis e Transexuais. Brasília, DF: Ministério da Saúde, 2013. Disponível em: <http:// bvsms.saude.gov.br/bvs/publicacoes/politica_nacional_saude_lesbicas_gays.pdf>. Acesso em: 6 fev. 2016.

BUTLER, J. Problemas de gênero: feminismo e subversão da identidade. Rio de Janeiro: Civilização Brasileira, 2003.

CERQUEIRA-SANTOS et al. Percepção de Usuários Gays, Lésbicas, Bissexuais e Transgêneros, Transexuais e Travestis do Sistema Único de Saúde. Revista Interamericana de Psicologia. Caribe, v. 44, n. 2, p. 235-245, 2010. Disponível em: <http://www.redalyc.org/ articulo.oa?id=28420641004>. Acesso em: 10 fev. 2016.

DEBUS, M. Manual de excelência em la investigación mediante grupos focales. In: ESPERIDIÃO, E. Reflexôes sobre a utilização do grupo focal como técnica de pesquisa. São Paulo: Fundação Editora de UNESP, 2004.

DONABEDIAN, A. An introduction to quality assurance in health care. New York: Oxford University Press, 2003. 
FOUCAUlT, M. História da Sexualidade I: A Vontade de Saber. Rio de Janeiro: Edições Graal, 1999.

GIANNA, M.C. CRT DST/Aids-SP implanta primeiro ambulatório para travestis e transexuais do país. BIS, Bol. Inst. Saúde (Impr.). São Paulo, v. 13, n. 2, p. 182-189, 2011. Disponível em: <http://periodicos.ses.sp.bvs.br/scielo.php?script=sci_arttext\&pid=S151818122011000200013\&lng=pt\&nrm=iso>. Acesso em: 11 jun. 2016.

GIDDENS, A. A transformação da intimidade: sexualidade, amor \& erotismo nas sociedades modernas. São Paulo: Ed. da Universidade Estadual Paulista, 1993.

GOMES, R. et al. Organização, processamento, análise e interpretação de dados: o desafio da triangulação. In: MINAYO, M.C.S.; ASSIS, S.G., SOUZA, E.R. (Org.). Avaliação por triangulação de métodos: abordagem de programas sociais. Rio de Janeiro: Editora Fiocruz, 2005, p. 185-221.

GRUPO GAY DA BAHIA (Org.). Assassinato de homossexuais (LGBT) no Brasil: relatório 2014. Salvadora, 2015. Disponível em: <https://homofobiamata.files.wordpress. com/2015/01/relatc3b3rio-2014s.pdf>. Acesso em: 13 out. 2017.

LIONÇO, T. Que direito à saúde para a população GLBT? Considerando direitos humanos, sexuais e reprodutivos em busca da integralidade e da equidade. Saúde e sociedade. São Paulo, v. 17, n. 2, p. 60-68, 2008. Disponível em: <http://www.scielo.br/scielo.php?script=sci_artte $\mathrm{xt} \&$ pid=S0104-12902008000200003>. Acesso em: 11 jun. 2016.

MELLO, L.; AVELAR, R.B.; MAROJA, D. Por onde andam as políticas públicas para a população LGBT no Brasil. Soc. estado. Brasília, v. 27, n. 2, p. 289-312, 2012. Disponível em: <http://www.scielo.br/scielo.php?script=sci_arttext\&pid=S0102-69922012000200005>. Acesso em: 18 ago. 2016.

MERHY, E.E. et al. Em busca de ferramentas analisadoras das tecnologias em saúde: a informação e o dia a dia de um serviço, interrogando e gerindo trabalho em saúde. In: MERHY, E.E.; ONOCKO, R. (Org.). Agir em saúde: um desafio para o público. São Paulo: Hucitec; Buenos Aires: Lugar Editorial, 1997.

MINAYO, M.C.S (Org.). Pesquisa social: teoria, método e criatividade. Petrópolis: Vozes, 2002. MULLER, M.I.; KNAUTH, D.R. Desigualdades no SUS: o caso do atendimento às travestis é 'babado'! Cad. EBAPE.BR. Rio de Janeiro, v. 6, n. 2, p. 1-14, 2008. Disponível em: $<$ http://www.scielo.br/scielo.php?script=sci_arttext\&pid=S1679-39512008000200002>. Acesso em: 20 fev. 2016.

PELÚCIO, L. Marcadores sociais da diferença nas experiências travestis de enfrentamento à aids. Saúde e Sociedade. São Paulo, v. 20, n. 1, p. 76-85, 2011. Disponível em: <http://www. revistas.usp.br/sausoc/article/view/29772/31653>. Acesso em: 10 fev. 2016.

RAMALHO, M.I. A sogra de Rute ou intersexualidades. In: SANTOS, B.S. (Org.). A globalização e as ciências sociais. 3. ed. São Paulo: Cortez, 2005. 
ROMANO, V.F. As travestis no Programa Saúde da Família da Lapa. Saúde e Sociedade.

São Paulo, v. 17, n. 2, p. 211-219, 2008. Disponível em: <http://www.revistas.usp.br/sausoc/ article/view/7589/9111>. Acesso em: 18 jun. 2016.

SANTOS, A.S. Problematizando o acesso e acolhimento de travestis e mulheres transexuais nos serviços de saúde. In: III Seminário Internacional Enlaçando Sexualidades, 1, 2013, Salvador. Anais..., Salvador, 2013, p. 71-79. Disponível em: < http://www.uneb. br/enlacandosexualidades/files/2013/06/Problematizando-o-acesso-e-acolhimento-detravestis-e-mulheres-transexuais-nos-Servi\%C3\%A7os-de-Sa\%C3\%BAde.pdf>. Acesso em: 10 ago. 2015.

TRAD, L.A.B. Grupos focais: conceitos, procedimentos e reflexões baseadas em experiências com o uso da técnica em pesquisas de saúde. Physis: Revista de Saúde Coletiva. Rio de Janeiro, v. 19, n. 3, p. 777-796, 2009. Disponível em: <http://www.scielo.br/scielo.php?script=sci_ar ttext\&pid=S0103-73312009000300013>. Acesso em: 15 fev. 2016.

UNGLERT, C.V.S. Territorialização em sistemas de saúde. In: Distrito Sanitário: o processo social de mudança das práticas sanitárias do Sistema Único de Saúde. São Paulo: Editora Hucitec, 1995, p. 221-235.

WORLD HEALTH ASSOCIATION. Division of Mental Health. Qualitative Research for Health Programmes. Geneva: WHA, 1994.

\section{Nota}

${ }^{1}$ B.O. Ferreira participou da concepção e execução das etapas do projeto, análise e interpretação dos dados e da redação do artigo. E.F. do Nascimento e L.M.I. do Monte participaram da revisão crítica relevante do conteúdo intelectual e da aprovação da versão final a ser publicada. J.I.S. Pedrosa participou da concepção do projeto, orientação da dissertaçáo e redação do artigo. 


\section{Abstract}

\section{Transvestites's experiences in access to SUS}

Recognizing that travestites face discrimination based on their gender identity, thus generating illness and suffering processes associated with associated stigmas, the study aimed to analyze and understand the experiences of transvestites about health care in SUS in Teresina-PI. For the methodological design, a qualitative research was carried out, involving six travestites residing in Teresina, who directly or indirectly access health services. Participants were selected by the Snowball methodological technique, and data collection was done through a focus group. The Method of Interpretation of Senses was used for analysis, treatment and interpretation of social phenomena. As a result and discussion, the following categories were identified: weaknesses in care and specialization in care. The study considered the need for more integration between the different social segments and health services, the qualification of the professionals to ensure the reception of transvestites and the urgency to reflect on the discriminatory character of the specialized services implanted by the SUS, even if they are a possibility of entering the health agency.

Keywords: gender identity; Unified Health System; equity. 